\title{
Translational Public Archaeology? Archaeology, social benefit, and working with offenders in Wales (Part 2)
}

\author{
Caroline Pudney \\ University of Chester, UK
}

This article reports on a second case study in the relationship between archaeology and social benefit through working with young offenders in Wales. Whereas a previous article (Pudney 2016), focused on the MORTARIA Project - an archaeological education project engaging adult offenders in South Wales - this study explores the distinctive methods and challenges faced by the subsequent Heritage Graffiti Project (HGP). This project faced similar, but also different, experiences to MORTARIA, involving different skills and technologies, as well as specific artistic engagement with place. The article considers the effectiveness of the HGP before reflecting on the two projects' shared implications for future, translational public archaeology projects that wish to work with offenders.

Keywords: public archaeology, community archaeology, social benefit, young offenders, heritage graffiti

\section{Introduction}

In a previous article, the author evaluated the MORTARIA project (Pudney, 2016), an archaeological education project that engaged adult offenders serving custodial sentences at HMP \& YOI Parc, Bridgend. This project was conducted by Cadw (n.d.), in partnership with G4S Care and Justice Services and with the support of Amgueddfa Cymru (National Museums Wales), during October 2012 to June 2014. This article focuses on the Heritage Graffiti Project (HGP), a heritage and arts-based project in which participants created a heritage-inspired graffiti mural. HGP took place alongside MORTARIA at HMP \& YOI Parc, but engaged young people involved in offending behaviour. The MORTARIA project focused on the attainment of skills for adult males involved in offending behaviour and while the Heritage Graffiti Project aimed to do the same, in reality, it was more successful in raising confidence level, a sense of pride and identity. Both projects sought to make heritage accessible to a clearly defined social group comprised of offenders, but also explore the social benefits of this engagement. This article addresses the HGP, with reference to MORTARIA, notably by assessing how 'translational' public archaeology projects can be. In a translational archaeology, the archaeologists work with other professionals to benefit a given community through a coproductive approach (Zimmerman, et al., 2010: 444). In such approaches, all of those involved transform specialist knowledge and skills into a positive, practical application.

At the time of the Heritage Graffiti Project, youth offending and child poverty were inextricably linked and were core priorities for the Welsh Government. As such, Cadw and HMP \& YOI Parc saw a unique opportunity to utilise heritage and the arts as a 'hook' to engagement and education. As with MORTARIA, the HGP worked with HMP \& YOI Parc to engage young offenders not only with archaeological material culture and monuments, but also with an attempt to imbue a sense of appreciation of the wider historic environment. The HGP aimed to help young people involved in offending behaviour by providing an opportunity to explore heritage and discover something new, which might, in turn, assist in broader restorative practice programmes. Its aim was not explicitly to 
alter attitudes towards heritage or increase appreciation of it (although this would, of course, result in beneficial consequences). Instead, through providing an opportunity to engage with heritage through a creative artistic process, it was anticipated that the project could explore what heritage might offer in the lives of young offenders. In turn, these projects contribute to the expanding discourse on the concept of translational archaeology (Crea, et al., 2014; Zimmerman, et al., 2010).

\section{Project environment}

The general prison environment has been discussed in relation to the MORTARIA project and therefore does not need re-iterating here (see Pudney, 2016). However, there are some differences in relation to the specific micro-environment of the young offenders' unit at the YOI Parc which warrant mentioning.

Custodial sentences for young people are usually a last resort, often substituted for alternative restorative justice measures (Crawford \& Newburn 2003). All young people (aged 15-17) at HMP \& YOI Parc are therefore often serving custodial sentences as a rehabilitative 'last resort'. Many have not completed secondary school and are encouraged to attend education classes where a varied curriculum is available. The prison promotes an inclusive, supportive, and progressive outlook on the role of education in reducing re-offending (HMP \& YOI Parc, 2014: see Education Mission Statement). As such, it offers as many engaging opportunities for the young people as possible. For example, the prison has writers in residence, links with local and national arts bodies including the Koestler Trust (www.koestlertrust.org.uk), Literature Wales, and even offers a unique version of the Hay Literature Festival named Hay-in-the-Parc (ITV, 2012).

The Young People's Unit (YPU) often presents many of the same risks as working with the adult population but it also presents its own, distinctive problems. It can be problematical and volatile at times due to the characteristics of the young people residing there. The Independent Monitoring Board (IMB) recorded a total of 226 reportable incidents from April 2014 to February 2015 at Parc, equating an average of 20.54 a month, with assaults, including fights, and self-harm being the main issues (Independent Monitoring Board, 2015: 6). This is not, however, a phenomenon unique to Parc. From anecdotal evidence, nearly all participants in the HGP were involved in some sort of violent offending behaviour, whether towards people or in the form of criminal damage.

The average day for a young person at Parc includes between 9.5 to 10.6 hours a day when they are outside of their cells (Independent Monitoring Board, 2012; 2013; $2014 ; 2015)$. The majority of this is spent in periods of education or association. The latter may for example, include counselling or specific anti- substance abuse sessions as part of their specific individual programme of support.

HGP, like MORTARIA, brought specific challenges in working in a secured environment. The equipment required a high-level clearance. Special dispensation was given for us to bring pressurised, graffiti spray cans into an environment where they are usually forbidden and without which, would have had a significant impact on the project. We were also permitted to bring in and use cameras (usually forbidden items), but under strict policies of use. No faces, keys or doors (locks), could be photographed and a highranking member of prison staff would check each digital photograph prior to us leaving each day, deleting those that may have been deemed controversial or potentially damaging to either the prison, participants or indeed ourselves. As for MORTARIA, there were restrictions on glass objects entering the prison during HGP since sharp, metal objects or anything that could potentially be used as a weapon. This would therefore 
impact upon the types of artefact (real and replica), that we were able to use during the workshop phases of the project. Everything and everyone entering the prison had to be checked and counted. This process was repeated on leaving each day.

\section{Heritage Graffiti Project}

As part of the wider programme of interventions, the project was led as a partnership between HMP \& YOI Parc and Cadw, like MORTARIA, but also involved a professional graffiti artist Bryce Davies of Peaceful Progress (www.peacefulprogress.org) and local film producer (and BAFTA Cyrmu Award winner), Ryan Owen Eddleston (www.filmryan.com). The project consisted of two sets of three half-day archaeology and artefact workshops, which were then used as inspiration for a graffiti art mural. The painting took place in two parts, over a total of five half-day sessions. Together, these sessions provided an environment in which personal and group creative responses to heritage could be expressed. The young people were fully integrated and responsible for the outputs throughout the project, which culminated in a public exhibition of their achievements within the Senedd, the seat of the National Assembly for Wales. The main evaluation methods utilised were observations and conversations recorded through the author's project diary, photography, a film put together using a time-lapse camera and vox-pops interviews, with basic quantitative data collection where available.

\section{Archaeology Workshops}

The project begun with workshops in which artefacts from Wales dating to range of prehistoric and historic periods were employed. By introducing the young people to archaeological artefacts, their material and function it was possible to immediately gain their attention (see Figure 1). Prior to the project we had been warned by YPU staff that if we were unable to gain their interest within the first few minutes, then the likelihood was that we would never be able to. This was achieved by simply placing the seemingly random assemblage on the table in the centre of the room. Participants' curiosity then led them to the table, where they began to engage with the tactile nature of the artefacts.

\section{Figure 1}

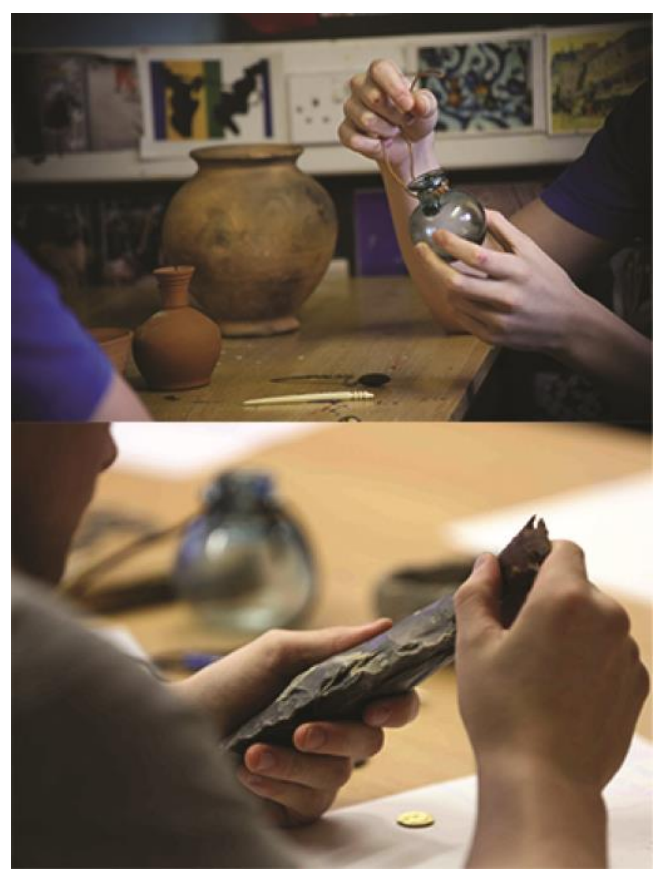


Having gained the participants' attention and entered into informal conversations about the objects, about us and about them, discussions moved on to what the artefacts may have meant to the people who created and used them. Themes of identity and community were considered, especially through the use of a mock grave assemblage. We asked questions such as: What does this tell us about the person buried there? What do the objects tell us about the culture from which they came? What items best represent us as individuals and as a culture? What would be the archaeological artefacts of the future? Trainers, iphones, laptops and drug paraphernalia were the things that stood out for these individuals as indicative of their own culture and identity. This was then followed with an activity focusing on our own impact upon the world through the objects that we use today. The final artefact workshop activity linked individual identity to wider cultural and social practice and concepts of heritage value. This incorporated discussions on cultural identity and the iconic buildings, structures and places that make their places important to them. In order to turn this into a mural, a brainstorming session began with Bryce, the graffiti artist (see Figure 2).

\section{Figure 2}

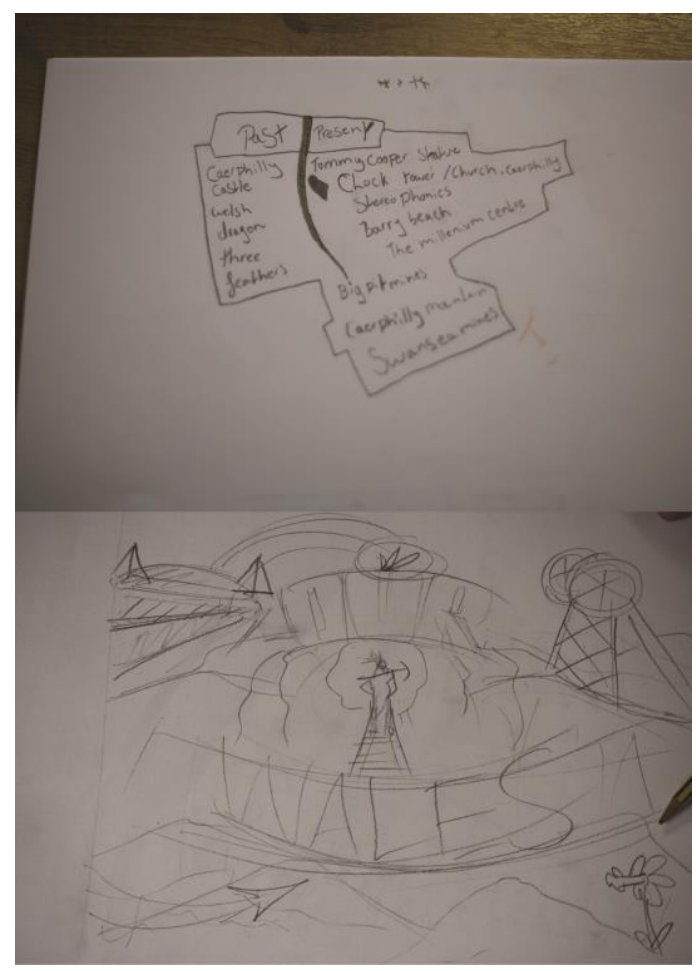

\section{Design Workshops}

The commonalities that linked each participant not only related to their current position in the prison and their offending behaviour, but between the areas from which they came. Each of the participants' home towns were historically inter-twined through Wales' industrial past: Cyfartha, Caerphilly, Cardiff and Merthyr Tydfil, all of which are connected through the coal industry of the $18^{\text {th }}$ and $19^{\text {th }}$ centuries. The mural plan therefore began to take shape with images of pitheads, mines and canals to represent the more recent past, amongst modern icons such as the Millennium Stadium, Cardiff, and the timeless backdrops of natural heritage: The Welsh Valleys and Brecon Beacons. 
The second part of the mural formed a timeline, moving chronologically back through the story of Wales' past (right to left along the mural), the images included Raglan Castle; the banner of Owain Glyndwr; the Hendre'r-ywydd Uchaf Farmhouse; a Welsh longhouse from Llangynhafal, Clwyd (Denbighshire), originally constructed in 1508 and moved to St Fagan's National History Museum in 1956; the Roman amphitheatre at Caerleon; the iconic faces of a Roman soldier and an Iron Age 'Silures'; the first Scheduled Ancient Monument in Wales - Pentre Ifan Neolithic burial chamber, Pembrokeshire, and back to the earliest human remains found in Wales, The Red 'Lady' of Paviland in Goat's Hole Cave (Gower Peninsula).

The design created a timeline of a fusion of participants' heritage and the heritage of Wales. The images and the places where chosen by the participants from a selection of Scheduled Ancient Monuments. These sites had been introduced during the workshops, the artefacts from some of which they had been handling. Workshops therefore acted as a starting point in their connection with an ancient and perhaps previously remote sense of place and time. Participants during this second set of workshops and design classes were less willing to promote their own ideas of heritage places than they were in the first set. The second part of the mural (although the first part of the timeline), represents a much more mediated past, based on the learning experiences provided in the workshops. This level of mediation was perhaps inevitable in a situation where prior knowledge of Wales' past and associated monuments was limited. The mural therefore reflected their view of the past and a sense of the longue-durée within the parameters of the resources provided. This timeline of images then culminated in the main focus of the mural, the image that they felt linked them as individuals today and their specific sense of place; the industrial and the modern.

The only thing remaining was a 'tag' or title. Through a heated discussion, suggestions such as 'Welsh Heritage', 'Wales Past and Present' and 'My Wales' were set aside (along with others which are not suitable to print here!), for the tag 'Our Wales'. This title began to instil a sense of pride amongst these young people, evident through their own suggestion that the chosen title was more inclusive, thus representing not only the immediate group but also their peers. Perhaps the most important thing was that the mural recognised all their contributions and appealed to their peers within the YPU. Their sense of achievement at arriving at this concept was further demonstrated by requests for their pencil sketches to be photographed for posterity, as if they would be more permanently recorded in digital form.

\section{Painting Workshops}

The painting workshops mostly consisted of painting the mural sketch on to a section of wall in the exercise yard in the young persons' unit using spray paint. With guidance from the graffiti artist the participants appeared nervous at first (see Figure 3), perhaps because this was something new and something previously 'forbidden'. There was also a perceived chance of going wrong, which took the young people out of their comfort zones.

\section{Figures $3 \& 4$}



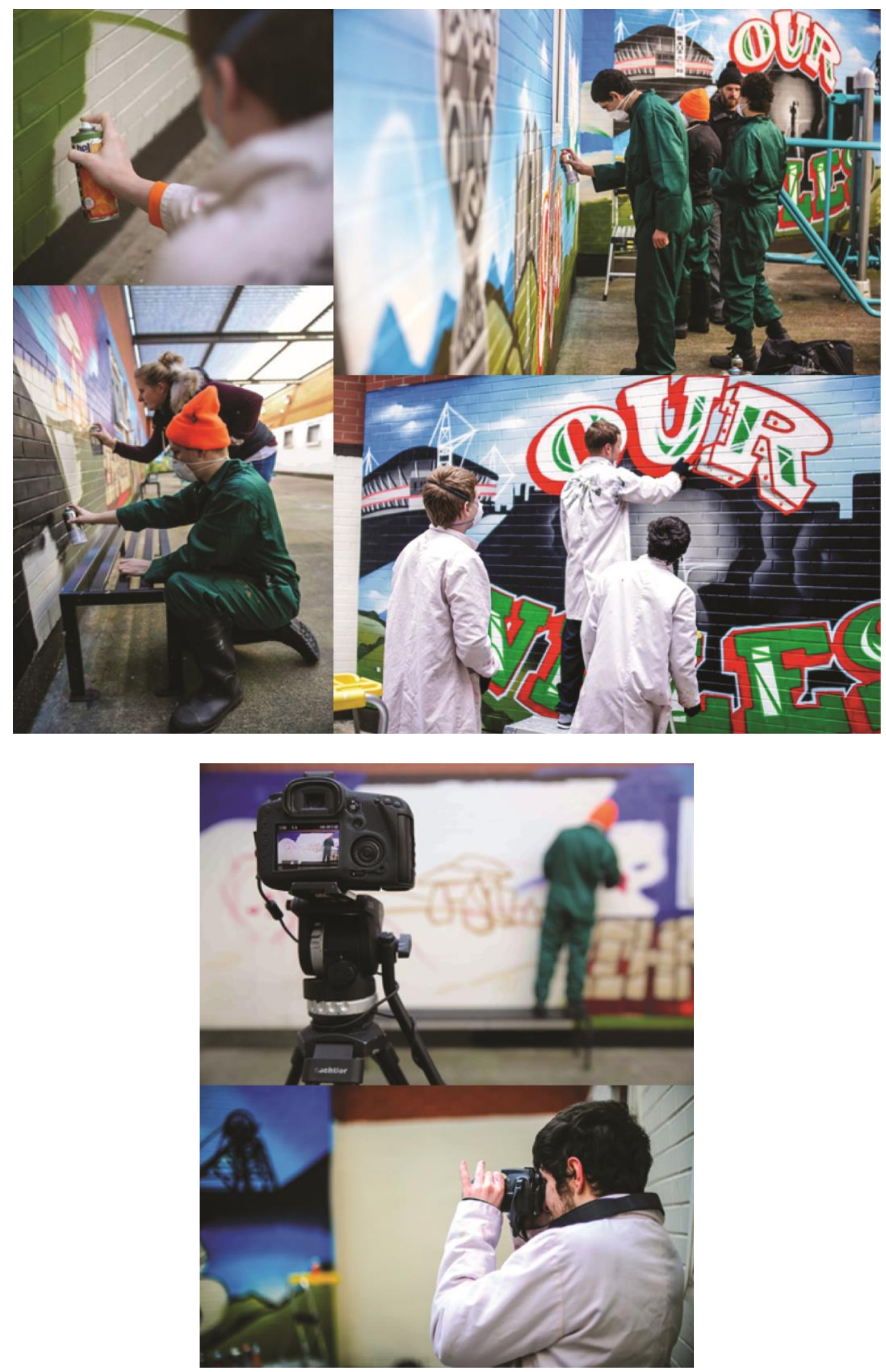

In a prison environment where the social and political dynamics are founded upon pride and self-image, any wrong move could dramatically challenge or even shift the hierarchy. The cameras set up to record the process (a static time-lapse camera and several roving cameras in the hands of Ryan), were clearly daunting for the participants, who initially refused to walk or stand in front of it, always preferring to move around the space beyond 
the sight of the lens. It was made apparent in conversation with one participant that any mistake could be documented in film and therefore perpetuated in record, potentially causing significant repercussions for the power-relations within the YPU.

As confidence grew and the group became increasingly comfortable in each other's company and ours, they began asking questions about the task they were carrying out, about us as individuals and the work that we did. Participants slowly became interested in the cameras, how they function and of course how much they cost, soon they were asking to have a go themselves. So while half the group painted, the other half were given a camera. They learnt how to use a professional digital SLR camera, about the different lenses, focus, zoom, angles and light and shade (see Figure 4). Before long it was a haven for paparazzi and the fixed time-lapse camera became a feature of the background - forgotten about and no longer something they were wary of standing in front of. They began thinking like a photographer who wanted to document the process and also to take more creative, artistic shots that could be used in an exhibition of their work. Ryan was often approached for advice and support in 'setting up' their more formal shots.

Within five sessions, the mural was complete (see Figure 5) and the material for the exhibition created.

\section{Figure 5}
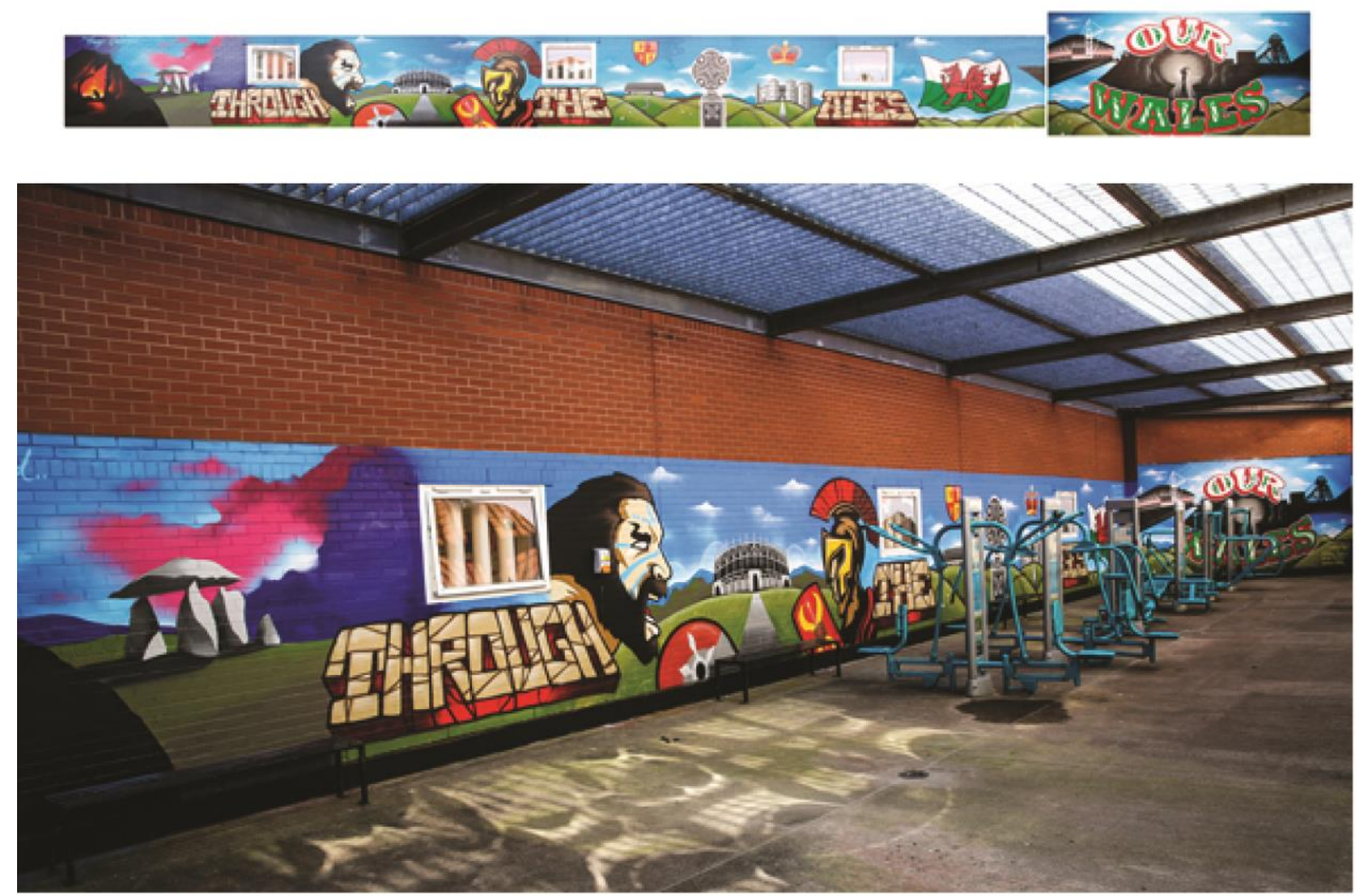

\section{Beyond the exercise yard}

In June 2014, an exhibition of the participants' achievements took place in the Senedd in Cardiff Bay - a public space within the Welsh Assembly where politicians, media, tourists 
and local residents frequent (http://cadw.gov.wales/about/news/heritage-graffitisenedd-exhibition/?lang=en). Then Minister for Culture and Sport, John Griffiths AM, launched the exhibition and many dignitaries attended the event, which showcased the photography and

film (http://cadw.gov.wales/learning/communityarchaeology/heritage-graffiti-

project/?lang=en ), put together during the project. A temporary exhibition of the work has also been on display at the National Roman Legionary Museum, Caerleon from January - October 2016. The exhibition included a printed banner of the final mural which will remain on display until further notice, where it has "become our 'timeline'" (pers. comm. Mark Lewis, Senior Curator). At the time of writing the exhibition has been seen by circa 104,000 visitors.

\section{Evaluation and Impact}

The feedback from the participants and the prison has been extremely positive, with a continued curation of the exhibition materials (at the time of writing remain on display around the prison). The challenge of measuring impact was already recognised by the MORTARIA project (Pudney, 2016). As with MORTARIA, HGP measured impact through standard prison evaluation questionnaires as well as through the author's project diary but also had the added outputs of the digital photographs and vox-pop interviews with participants.

Nine young people participated in the project, c. 70\% of whom were of a white, British ethnic background, like MORTARIA, largely reflecting the general demographic of the prison population. Unlike MORTARIA, the project did not include any form of accreditation but participation was permitted as an incentive for good behaviour. Perhaps on a broader level, one of the biggest impacts observed by the author was the demonstration of how individuals need to take responsibility for the consequences of their actions and behaviour. This was particularly evident when one participant was excluded from the project half way through due to unacceptable behaviour the previous evening.

Trust and responsibility were key factors that were evident throughout the project especially from the author's observations and discussions with custodial staff within the YPU. The trust instilled upon those delivering the project and upon the participants was hugely important to both. The young people were being trusted to use 'forbidden' pieces of equipment, such as cameras and spray cans. Positions of trust like this are consequently of vital importance in the rehabilitation of these young people and also the trust instilled upon the participants of MORTARIA was equally significant (Pudney, 2016). Importance of meaningful and sustained relationships of trust in the rehabilitation of offenders has been more widely attested (Robinson, 2005; Rowe \& Soppitt, 2014). There was also a degree of trust instilled upon us, as outsiders who were entering into their space. This trust and respect was reciprocal but had to be earned.

As with the MORTARIA Project, monitoring behavioural change was difficult. For the most part the participants continued to be fully engaged with the project throughout, although attention spans peaked and troughed throughout each session. Despite this all participants expressed a keen desire to learn new skills relating to painting and photography. Discussions during the project indicated that knowledge of their heritage had increased, and they began to appreciate the value of Welsh heritage beyond their favourite or familiar places. These elements were expressly voiced in the film documenting the project. 
A major success of the project became noticeable after break time, half way through painting the 'Our Wales' motif. The mural was almost complete but we had to pack up for 20 minutes while the residents of the YPU used the space for break. This gave the participants a chance to mix with their peers, in front of the mural. On our return to the yard after break the participants were full of energy, their faces displayed wide smiles, and their whole demeanour was altered. They were standing tall and evidently very proud of what they had achieved. While previously they were perhaps inwardly pleased with what they had done so far, it was the commendations from the other young people that literally made each participant 'buzz'.

They never believed we done that - I told them we did, we designed it, painted it and have been using cameras and stuff to photograph it. This is gonna be here forever! All the boys are gonna see our work long after we've gone and they'll know that we did it.

(Participant, aged 16)

It has a positive effect on me 'cause, like, when I come out here I can look at it and I can think I done that.

(Participant, aged 15)

They said it was good. Makes me proud, like, knowing that we did it. (Participant, aged 16)

The interest from the other young people, their validation, and the sense of pride and achievement that it instilled upon the participants is not something that can be measured using figures and statistics but it was a very real outcome of the project. This is the type of impact that is hoped will stay with each participant and help to show them the types of things that they are able achieve. Pride was further evidenced by participants' requests for a photograph of themselves in front of the mural that they could take home with them on their release. They were also keen that their names be added to the mural, ensuring both their individual legacy and that of the group as a whole. At the time of writing, the mural has not suffered any vandalism since it was completed in 2012. This also emphasises the value of the mural to those who had no involvement in its creation.

The awareness and appreciation of graffiti amongst the participants also became very apparent during discussions on where it is ' $\mathrm{OK}$ ' to paint. Cardiff alone has spaces designated for graffiti artists to use and where there are clear unwritten rules surrounding what is acceptable and what is not, thus highlighting the responsible nature of many artists today. This was something that the graffiti artist in particular was able to contribute to the project, having been involved in the graffiti scene for a number of years (possibly on both sides of the law). We therefore also discussed what constitutes 'good' graffiti or graffiti with heritage value (McAuliffe, 2012; Merrill, 2011) - these were all lively and thought provoking but importantly, relaxed and informal group conversations rather than through a more formalised, teaching environment. Significantly, little persuasion was needed when discussing heritage value of sites and monuments and appropriate behaviour, yet the concept of graffiti art with heritage value was more thought-provoking.

I used to think graffiti was just people spraying their names. I didn't think, like, you could do artwork like that. I've got a whole different opinion on it. (Participant, aged 16) 
This project was clearly successful in helping create a short-term sense of pride and identity for participants. It is hoped that participants' experience has left a lasting impact on them, although as discussed in relation to MORTARIA (Pudney 2016), identifying and measuring the longer-term effects of a project like this are often one of the major shortcomings, with the quantification of longer-term impact proving problematic. It therefore remains unclear whether actual attitudes towards heritage have altered in any way, or how the mural is considered by current residents of the YPU who were not involved in the project but who interact with it on a daily basis. This latter point could however, be addressed through re-visiting the YPU and interviewing the residents.

\section{Moving towards a translational archaeology}

Wider research undertaken on strategies to help reduce re-offending demonstrates how education and associated opportunities like this are invaluable and immeasurable (Bayliss 2003; Clements 2004; Crawford and Newburn 2002; Duwe and Clark 2014; Esperian 2010; McGuire 2003; McLaren 2000). For young people involved in offending behaviours to have new experiences and skills, build bonds with other young people and adults from various walks of life, through working as part of a team they have the potential to attain self-belief, confidence and a sense of achievement (Crawford and Newburn 2002; McLaren 2000). This impact however, as with the MORTARIA Project, cannot easily be articulated (Friendship et al. 2003; Koehler et al. 2013; Merrington and Stanley 2014), especially using the types of performance statistics that heritage outreach and community archaeology projects are so often required to use in their evaluation.

Echoing issues at the core of Simpson's work (Simpson 2009; Simpson and Williams 2008), future sustainability and evaluation strategies need to be re-addressed, specifically for public archaeology projects that are centred on social benefit. This has been highlighted in the main shortcomings of the project discussed here and in Part 1 of this study. Firstly, the sustainability and continued (if not enhanced) success of the projects require consideration. While the prison continues to offer a range of opportunities for inmates, the MORTARIA project was largely dependent on the author's position at Cadw. Although contingency plans were identified in order to continue the project in a slightly different format, these rely on the workloads of staff that do not have the specific remit that a community archaeologist might have. Even with the best of intentions, the risk of external factors affecting the sustainability of the project is increased considerably. Secondly, anecdotal evidence from these projects has tended to demonstrate the real impact for the individuals involved. Unfortunately this does not usually conform to the ways in which many funding sources or authorising bodies collect evidence for impact. Anecdotal evidence is not generally catered for in the Key Performance Indicators collected by the Welsh Government. Finally, other studies on interventions aimed at young people involved or at risk of being involved in offending behaviour, run the risk of being more damaging than doing nothing (Petrosino et al. 2003; 2013). Although these interventions aimed to deter young people from eventually ending up in prison therefore addressing a different stage of the crime-cycle to that of participants in HGP (who were already in serving custodial sentences), the authors highlighted that rigorous evaluation is required to measure whether an intervention has been positive or detrimental and in what ways. In order for projects such as MORTARIA and HGP to be fully translational, they require to be transformed into evidence-based policy that is grounded in comprehensive evaluation. 
Qualitative data on the impact of public or community archaeology is often captured through questionnaires that convert qualitative responses into quantitative data (see Lewis, 2014). Such evaluation methods are often utilised by the museums sector (Falk and Dierking 1992; Goulding 2000; Packer 2008; de Rojas and Camarero 2008). However, as some critical approaches to community archaeology have demonstrated (Simpson 2009; Simpson and Williams 2008), despite their innovative approaches, much of the evidence is captured through leading questions, which limits the responses' relevance (especially in the case of Lewis 2014 and Packer 2008). As yet, archaeologists do not appear to have found a successful way beyond this. There is a case to be made for the use of universal, methodological approaches for community archaeology projects, including their evaluation (Moser et al. 2002; Tully 2007), however, despite the need for methodologies to be flexible and re-evaluated (Tully 2007, 179), universal criteria are perhaps too rigid an approach for projects that involve vulnerable groups such as offenders and young people either at risk of or involved in offending behaviour. For example, Tully's methodology is more suited to '...a particular power dynamic that is existent in the archaeological projects for which they are designed.' (Isherwood, 2009: 19).

In the eyes of the heritage organisations and politicians involved, both the MORTARIA and Heritage Graffiti projects were successful in meeting Government priorities. Huw Lewis AM (then Minister for Heritage, Culture and Sport), visited one of the MORTARIA workshops and his successor, John Griffiths visited the Heritage Graffiti mural, to meet those who created it. Both mentioned the projects in the National Assembly sessions and in press releases. G4S Care and Justice Services also noted the project to demonstrate their commitment to offering engaging and varying interventions at Parc, something they were applauded for (Independent Monitoring Board 2012; 2013; $2014 ;$ 2015). The Independent Monitoring Board (2012) listed the project as an 'outstanding achievement'. Finally, Cadw used the projects to demonstrate how they were addressing Programme for Government and as evidence of their work in numerous official responses to Assembly Questions in 2013-14.

The success of MORTARIA and HGP was however, dependent upon the individuals involved: archaeologist, prison staff, other specialists and participants. A prison environment can be a daunting one and not everyone is comfortable or suitable to work within it. While the author was provided with basic training relating to self-protection and participated in an initiation into some of the prison systems, the setting is challenging and volatile. This has implications of the facilitation of a prison-based project. It requires a range of social skills on both sides but the ability to relate to the participants on many levels should be a fundamental requirement of any heritage professional entering into such a project.

In such a dynamic, changeable environment it was vital that the person delivering the workshops had a plan B, C, and even D up their sleeve especially in case the participants lost interest. Flexibility was crucial. Despite being a captive audience, the MORTARIA participants were vocal in any dissatisfaction or disinterest. The interest of the specialist does not always translate on to the interest of the participant. This echoes the argument that methodologies for community archaeology projects have to be open to significantly revising their original aims (Tully, 2007: 171) or indeed any other details of the project, often at short notice. Such project should therefore include an organic approach that is flexible rather than one bound by rigid parameters.

The Heritage Graffiti Project, like MORTARIA, did on some level, help to make heritage more accessible, not only to those directly involved in the project, but also those 
who interact with the mural itself. While an increased appreciation of heritage among those involved in offending behaviour may help to reduce heritage crime, making a direct link to these projects is hugely problematic. In the case of the MORTARIA, the social impact lies in what the project provided for the participants and what the participants were able to provide the heritage specialists, not specifically changes in values of heritage itself. During the project, new relationships were forged between inmates, staff and outsiders. The capacity for heritage professionals to include offenders in outreach projects was increased. The atmosphere within the particular parts of the prison shifted. Most importantly, the rehabilitative environment was enhanced during the life-span of the project. It was the engagement with something different, which appears to have provided the main benefit for participants.

It was a new experience, meeting new people, learning new things (Participant, aged 16)

Yet how do we begin to transform knowledge gained through the MORTARIA and HG Project into some form of practical application with demonstrable benefits? To begin to develop the translational legacy of the MORTARIA and HG Projects we need to expand our collaborative networks even further. Collaboration with social sciences is required in order that project- specific, tailor-made methodologies are to be effective, especially those linked to evaluation, much along the lines of the ethno-archaeological approach suggested by Simpson and Williams (2008). As Zimmerman and his colleagues (2010: 445) have identified, in order for archaeology to be translational collaboration with people who have the problem is required, as well as wider partnerships in which power is shared so that research agendas and goals can be equally negotiated, solutions reached and assessed. This way knowledge created through a variety of disciplines and organisations - namely (public) archaeology, psychology, criminology, national offender management, prison and probations services, and education - could help to create a much more sustainable project design which could be implemented at a range of offender management institutions. The collaborative net therefore, requires casting much wider than it was for MORTARIA and HGP and there is great, untapped value in pursuing and developing more extensive, co-productive approaches to working with offenders in the UK.

\section{Acknowledgements}

The projects focused on in this article would not have been possible without the Welsh Government, Cadw, Amgueddfa Cymru, Her Majesty's Prison and Young Offenders Institution, Parc, G4S and the Ministry of Justice. Particular thanks go to Laurence Bater and the team at HMP Parc, Jon Berry and Polly Groom (Cadw) and Mark Lewis and Mark Redknapp (Amgueddfa Cymru). Faye Sayer and Howard Williams were kind enough to read previous drafts of the article and provide comment. Thanks also to the editors' and anonymous reviewers' constructive comments. Any mistakes, inaccuracies or oversights remain the author's own. 


\section{Note on contributor}

Caroline Pudney is Lecturer in Archaeology at the University of Chester. Her main research focus is on Iron Age and Roman Britain, particularly the agency of objects. As a former community archaeologist, Caroline also has a specific interest in debates surrounding public archaeology.

Correspondence to: Department of History \& Archaeology, University of Chester, Parkgate Road, Chester, CH1 4BJ. Email: c.pudney@chester.ac.uk

\section{Bibliography}

Bayliss, P. 2003. Learning behind bars: time to liberate prison education. Studies in the Education of Adults 35(2), 157-172.

Cadw, n.d. Community Archaeology. Cadw Copyright 2015. Available at: http://cadw.gov.wales/learning/communityarchaeology/?lang=en Accessed 13/11/2015

Clements, P. 2004. The Rehabilitative Role of Arts Education in Prison: Accommodation or Enlightenment?. International Journal of Art \& Design Education, 23, 169-178.

Crawford, A. and Newburn, T. 2002 Recent Developments in Restorative Justice for Young People in England and Wales: Community Participation and Representation. The British Journal of Criminology 42(3), 476-495.

Crawford, A. and Newburn, T. 2003. Youth Offending and Restorative Justice. Implementing Reform in Youth Justice. Abingdon: Routledge.

Crea, G., Dafnis, A., Hallam, J., Kiddey, R., \& Schofield, J. 2014. Turbo Island, Bristol: excavating a contemporary homeless place. Post-Medieval Archaeology, 48(1), 133-150

Duwe, G. and Clark, V. 2014. The Effects of Prison-Based Educational Programming on Recidivism and Employment. The Prison Journal 94 (4), 454-478.

Esperian, J. H. 2010. The Effect of Prison Education Programs on Recidivism Journal of Correctional Education 61(4), 316-334

Falk, J. H. and Dierking, L. D. 1992. The Museum Experience. Washington, DC: Whalesback Books

Friendship, C., Falshaw, L. and Beech, A. R. 2003. Measuring the real impact of accredited offending behaviour programmes. Legal and Criminological Psychology, 8, 115-127.

Goulding, C. 2000. The Museum Environment and the Visitor Experience. European Journal of Marketing, 34 (3/4), 261-278.

HMP \& YOI Parc. 2014. Welcome to HMP \& YOI Parc. http://www.hmpparc.co.uk. Date Accessed: $09 / 11 / 2015$. 
Independent Monitoring Boards 2012. Annual Report. HMP \& YOI Parc, March 2011 - February 2012.

Independent Monitoring Boards 2013. Annual Report. HMP \& YOI Parc, March 2012 - February 2013.

Independent Monitoring Boards 2014. Annual Report. HMP \& YOI Parc, March 2013 - February 2014. Monitoring Fairness and Respect for People in Custody

Independent Monitoring Boards 2015. Annual Report. HMP \& YOI Parc, March 2014 - February 2015. Monitoring Fairness and Respect for People in Custody

Isherwood, I. 2009. Community Archaeology. A study of the conceptual, political and practical issues surrounding community archaeology in the United Kingdom today. University of Manchester: Unpublished PhD Thesis

ITV 2012. The Hay in the Parc Festival. 20th June 2012. (C) Copyright ITV plc 2015 http://www.itv.com/news/wales/story/2012-06-20/the-hay-in-the-parc-festival/ Accessed: $09 / 11 / 2015$.

Koehler, J. A., Lösel, F., Akoensi, T. D., and Humphreys, D. K. 2013. A systematic review and metaanalysis on the effects of young offender treatment programs in Europe. Journal of Experimental Criminology 9(1), 19- 43.

Lewis, C. 2014. 'Cooler than a trip to Alton Towers': Assessing the Impact of the Higher Education Field Academy, 2005-13. Public Archaeology, 13(4), 295-322.

McAuliffe, C. 2012. Graffiti or Street Art? Negotiating the Moral Geographies of the Creative City. Journal of Urban Affairs 34, 189-206. doi: 10.1111/j.1467-9906.2012.00610.x

McGuire, J. (ed.) 2003. Offender Rehabilitation and Treatment: Effective Programmes and Policies to Reduce Re-offending. Chichester: John Wiley and Sons.

McLaren, K. 2000. Tough Is not Enough: Getting Smart About Youth Crime: A Review of Research on What Works To Reduce Offending by Young People. Wellington: New Zealand Ministry of Youth Development.

Merrill, S. O. C. 2013. Graffiti at Heritage Places: Vandalism as Cultural Significance or Conservation Sacrilege? Time and Mind: The Journal of Archaeology, Consciousness and Culture $4(1), 59-75$

Merrington, S. and Stanley, S. 2014. 'What Works?': Revisiting the Evidence in England and Wales. Probation Journal 51(1), 7-20.

Moser, S., Glazier, D., Phillips, J. E., el Nemr, L. N., Mousa, M. S., Aiesh, R. N., Richardson, S., Connor, A., and Seymour, M. 2002. Transforming Archaeology through Practice: strategies for collaborative archaeology and the Community Archaeology Project Quseir, Egypt. World Archaeology 34(2), 220-48.

Packer, J. 2008. Beyond Learning: Exploring Visitors' Perceptions of the Value and Benefits of Museum Experiences. Curator: The Museum Journal 51(1), 33-54.

Petrosino, A., Turpin-Petrosino, C., \& Buehler, J. 2003. Scared Straight and other juvenile awareness programs for preventing juvenile delinquency: A systematic review of the randomized 
experimental evidence. The Annals of the American Academy of Political and Social Science, 589(1), 41-62

Petrosino, A., Turpin-Petrosino, C., Hollis-Peel, M. E., \& Lavenberg, J. G. 2013. 'Scared Straight'and other juvenile awareness programs for preventing juvenile delinquency. The Cochrane Library. http://onlinelibrary.wiley.com/doi/10.1002/14651858.CD002796.pub2/pdf Accessed on $24 / 02 / 2017$

Pudney, C. 2016 Romans and Reducing Recidivism: Archaeology, social benefit, and working with offenders in Wales. Part 1. Public Archaeology

Robinson, G. 2005 What works in offender management? Howard Journal of Criminal Justice 44: $254-268$

de Rojas, C. and Camarero, C. 2008. Visitors' experience, mood and satisfaction in a heritage context: Evidence from an interpretation center. Tourism Management 29(3), 525-537.

Rowe, M., \& Soppitt, S. 2014. 'Who you gonna call?'The role of trust and relationships in desistance from crime. Probation Journal, 61(4), 397-412.

Simpson, F. 2009. The Values of Community Archaeology: A Comparative Assessment. University of Exeter: Unpublished PhD Thesis.

Simpson, F. and Williams, H. 2008. Evaluating Community Archaeology in the UK. Public Archaeology 7(2), 69-90

Tully, G. 2007. Community archaeology: general methods and standards of practice. Public Archaeology 6(3), 155-187

Zimmerman, L. J., Singleton, C., \& Welch, J. 2010. Activism and creating a translational archaeology of homelessness. World Archaeology, 42(3), 443-454. 